\title{
Discussion on the logic mechanism and implementation strategy of unblocked "Dual Circulation" Development Pattern blocking point
}

\author{
Song Ling ${ }^{1}$ \\ ${ }^{1}$ International Bussiness School Shaanxi Normal University, Xi'an,China
}

\begin{abstract}
The implementation of the strategy of "a new development pattern with domestic and international cycles as the main body and mutual promotion of domestic and international dual cycles" is of great strategic significance for promoting the high-quality development of my country's economy, comprehensively deepening reforms, and promoting high-level opening up. This article starts from the unblocked double-circle block point, through the explanation of the background meaning of the construction of the new development pattern, the analysis of the scientific connotation of the new development pattern, and the study of the implementation strategy to promote the new development pattern.This is a major strategic decision to keep pace with the pulse of economic development in the new era, and has important practical significance for activating and digging into the domestic market space and responding to the complex and complex impact of globalization.
\end{abstract}

\section{Introduction.}

Facing the complicated political and economic situation, in May 2020, the central government proposed to gradually form a development strategy of "a new development pattern with domestic and international cycles as the main body and mutual promotion of domestic and international dual cycles" [1]. The proposal of this strategic pattern is not only a guideline and strategic deployment for economic development during the 14th Five-Year Plan period, but also a major scientific innovation in theories and policies to explore long-term development trends from short-term fluctuations in the new situation.

\section{The era background and practical significance of the construction of the new development pattern}

The global pandemic of the new crown epidemic in 2020 has triggered a global economic recession, and has also had a very large impact on the Chinese economy, and the short-term blow will be very severe. However, as the Chinese economy has been the first to control the epidemic since March 2020, the economy has shown signs of recovery.From the demand side, data from the National Bureau of Statistics show that my country's total retail sales of consumer goods in the first half of the year fell by $11.4 \%$ year-o n-year, national fixed asset investment fell by $3.1 \%$ year-on-year, and real estate development investment increased by $1.9 \%$ yearon-year. Due to the raging overseas epidemic and shrinking external demand, the import and export situation is still severe. In the first half of the year, the import and export value fell $3.2 \%$ year-on-year. ${ }^{[2]}$ From the supply side, the resumption of work and production has accelerated, the interruption of the manufacturing supply chain has been alleviated, and the service industry has generally recovered. According to data from the National Bureau of Statistics, in the first half of 2020, the added value of the secondary industry fell by $1.9 \%$ year-on-year; the added value of the tertiary industry fell by $1.6 \%$ year-on-year. ${ }^{[3]}$ The impact of the epidemic on the service industry has led to the integrated development of online and offline services, and new models such as online retail, food delivery, online education, and online diagnosis and treatment continue to grow and develop. Throughout the course of China's economic development, speeding up the construction of a new development pattern is an active choice made in accordance with the laws of my country's economic development. In the 1980 s, the rise of the element-based international division of labor lowered the threshold for my country to participate in the international cycle. After Deng Xiaoping's southern speech in 1992, he further integrated into the global division of labor system. In 2001, he joined the World Trade Organization and took the international cycle as a reference. The main export-oriented economic system was established. Although my country has successfully integrated into the global industrial chain and value chain, 
and has achieved rapid economic growth and industrialization, its excessive dependence on foreign markets has also made my country's economy vulnerable to external risks. Since 2006, the trade dependence of the whole country and the eastern region has shown a downward trend. After the 2008 financial crisis, it has gradually turned to internal circulation.

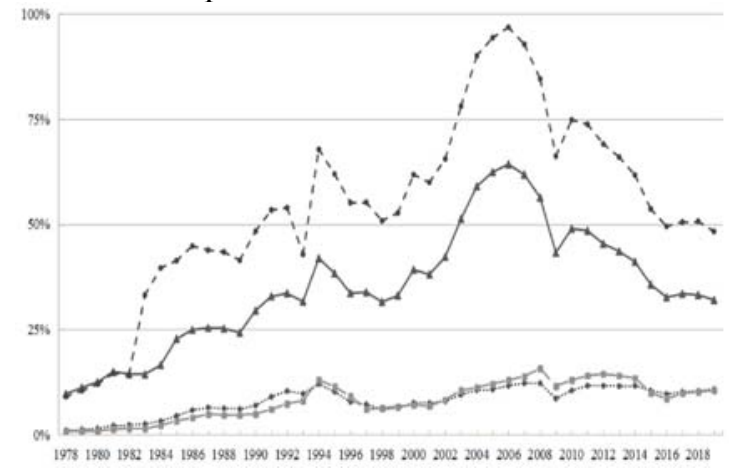

$\longrightarrow$ National trade dependence $\rightarrow-$ Eastern trade dependence
$\cdots . . . .$. Central China's trade dependence - Western trade dependence

Figure 1. Trade dependence of the whole country, the eastern region, the central region, and the western region

\section{Correctly understand the scientific connotation of the new development pattern}

\subsection{The scientific connotation of economic cycles}

General Secretary $\mathrm{Xi}$ Jinping pointed out at the Entrepreneur Forum on July 21, 2020: "With the domestic cycle as the main body, it is by no means a closed door to operate in a closed manner, but by leveraging the potential of domestic demand to better connect the domestic market with the international market., Make better use of the two international and domestic markets and two resources to achieve stronger and more sustainable development." [4] That is to say, in the new development stage, although the domestic economic cycle and the international economic cycle have primary and secondary effects, both Complementing each other and being dialectically unified, both are aimed at realizing the development of our country's economy and the improvement of people's living standards. What exactly is an economic cycle? From a geographical perspective, economic cycles are divided into international economic cycles and domestic economic cycles. The theory of international economic cycles can be traced back to Adam Smith's theory of labor division. He believes that division of labor can promote the improvement of labor productivity, and the absolute advantage between countries is the basis for the formation of international division of labor and international trade. In response to the problem of the lack of explanatory power of the absolute advantage theory, David Ricardo proposed the comparative advantage theory, which believed that comparative advantage is the basis and principle for countries to exchange commodities. Regarding the issue of domestic economic cycles, there were similar views as early as the Mercantilist school. For example, Thomas Meng advocated importing raw materials and exporting industrial products, using the power of the state to protect the domestic market, restrict the export of natural resources, implement tariff protection, and develop The country's manufacturing and high-end industries. Liszt believes that when the country's economy is in a relatively backward stage, trade protection, development of domestic productivity and construction of a unified domestic market should be implemented. In response to the phenomenon of the Great Depression and the insufficient explanatory power of existing theories, Keynes proposed that demand will affect employment and national economic development, while insufficient demand is caused by psychological factors. Therefore, national intervention policies are needed to stimulate consumption and investment and promote effective Demand growth.

\subsection{The new pattern of Marx's theory of capital circulation and turnover}

Marx discussed the cycle of production, distribution, exchange, and consumption in "Introduction to a Critique of Political Economy": "Production is the starting point, consumption is the end, and distribution and exchange are the intermediate links." [5] No link is possible. Lack, forming a cyclical movement again and again, and there are many derived small cycles that intersect each other. And each link is cross-influenced and integrated. This is the common operating law of any economy and society, but the degree of development is different, especially after the high-level development of productivity, socialist society is no exception. Otherwise, human economic activities will cease. Or the economic and social cycle is hindered, from a crisis to a crisis, to a change. This cyclic movement never ends.

Constructing a new development pattern in which the domestic big cycle is the main body and the domestic and international double cycles promote each other includes four links of production, distribution, circulation, and consumption. The cycles of these four links form the cycle of the national economy. General Secretary Xi Jinping pointed out that to build a new development pattern, we must insist on expanding the strategic basis of domestic demand, so that production, distribution, circulation, and 
consumption can rely more on the domestic market, forming a virtuous circle of the national economy. It can be seen that the general secretary's definition of the new development pattern is in the same line as Marx's theory.

\section{4 the implementation strategy to promote the new development pattern}

The construction of a new development pattern involves the adjustment and optimization of the supply and demand pattern, demand pattern, distribution pattern, production pattern, technological pattern, and open pattern of economic development. It is a systematic and in-depth change that concerns the overall situation. Therefore, it is necessary to formulate an implementation strategy to guide and accelerate the construction of a new development pattern.

\subsection{Persist in promoting industrial upgrading}

Promote industrial upgrading and upgrade the modernization level of the industrial chain. First, it is necessary to improve the domestic division of labor system and form a complete industrial chain. Different domestic divisions of labor must be formed in accordance with the advantages of resources and talents, and a complete industrial chain must be built in the country. It is necessary to build an independent, controllable, safe and reliable industrial chain and supply chain, strive to have alternative sources for important products and supply channels, and form a complete industrial backup system. Second, give full play to the advantages of a major country to promote industrial upgrading. Take advantage of China's large population and large differences in economic development, and accelerate the construction of a new pattern of regional coordinated development. Promote the development of high-tech and capitalintensive industries in the eastern region, transfer some industries that no longer have competitive advantages in the eastern region to other countries, or give priority to transfer to the central and western regions, and promote the industrialization, urbanization, and modernization of the central and western regions. Third, deepen the supplyside structural reforms and upgrade the modernization level of the industrial chain. It is necessary to start from the supply side to solve the problem of structural imbalance and improve the overproduction of low-end products on the supply side and the shortage of mid-tohigh-end products. Improve the modernization level of the industrial chain, produce differentiated products, and better meet the needs of domestic and foreign markets.

\subsection{Adhere to technology leadership}

Adhere to the advancement of science and technology, and enhance the effectiveness of the new national system. To give full play to the advantages of the new nationwide system, it is necessary to achieve breakthroughs in key core technologies. Efforts to improve the technological content of development, master core technologies, solve the problem of stuck necks, and promote high-quality economic development. In the fields of artificial intelligence, integrated circuits, biopharmaceuticals, aerospace, etc., carry out necessary international coordination and focus on tackling key problems, and strive to achieve breakthroughs in key areas related to the national economy and people's livelihood as soon as possible. The strategic planning and implementation of the frontier basic theories of natural sciences should be carried out as soon as possible, and the training of talents should be strengthened. Adhere to the principle of bringing in foreign talents, especially Chinese scientists, and domestic talent training simultaneously, and continuously improve the quality of talent training. Strengthen the protection of intellectual property rights, promote the marketization of patented technologies, and build a collaborative innovation system of industry, university and research.

\subsection{Adhere to the people's livelihood orientation and enhance the strategy of expanding domestic demand}

Adhere to the people's livelihood orientation and enhance the effectiveness of the strategy of expanding domestic demand. Persist in people's livelihood-oriented production to better meet the needs of the people's lives. It is necessary to change from the past production goals oriented by international standards and exports to the goal of meeting Chinese standards and meeting the needs of Chinese people in production and life, and promote the localization and sinicization of export-oriented enterprises. Promote the development of urbanization and increase investment in rural infrastructure. Compared with countries with the same level of industrialization, China's urbanization rate, especially the urbanization rate of registered population, is still relatively low, and traditional infrastructure in many places is still relatively backward. It is necessary to further liberalize the household registration policy and promote the process of urbanization. At the same time, it is necessary to speed up the construction of new rural areas, increase investment in rural infrastructure, and improve farmers' production and living conditions.

In 2019, my country's total retail sales of consumer goods was 41.2 trillion yuan, ranking it second in the world as the world's second largest consumer, and it is constantly approaching the United States, which ranks first...Consumer demand has become the main driving force for economic growth. Since the "13th Five-Year Plan", the contribution rate of domestic demand to my country's economic growth has remained above $85 \%$, of which the contribution rate of final consumption has exceeded $55 \%$, and it was $57.8 \%$ in 2019 . The proportion of final consumption in GDP has increased steadily. In 2019 Reached 55.4\%. The world's second-largest consumer country is constantly approaching the United States, which ranks first (see Figure 1). The rapid growth of residents' service consumption has driven the continuous upgrading of the consumption structure. In 2019, the residents' Engel coefficient was $28.2 \%$, down 2.4 percentage points from the end of the "Twelfth Five- 
Year Plan" (2015), and the proportion of residents' service consumption rose from $41.1 \%$ to $45.9 \%$. Emerging consumption models represented by online shopping and mobile payment have developed rapidly. In 2015, my country's online retail transaction volume ranked first in the world, reaching 10.6 trillion yuan in 2019. The sudden new crown pneumonia epidemic has restricted people's offline consumption activities and objectively helped further online consumption patterns. More importantly, consumer demand has become the main driving force for economic growth. Since the "13th Five-Year Plan", the contribution rate of domestic demand to my country's economic growth has remained above $85 \%$, of which the contribution rate of final consumption has exceeded $55 \%$, and it was $57.8 \%$ in 2019 . The proportion of final consumption in GDP has increased steadily. In 2019 Reached $55.4 \%$.

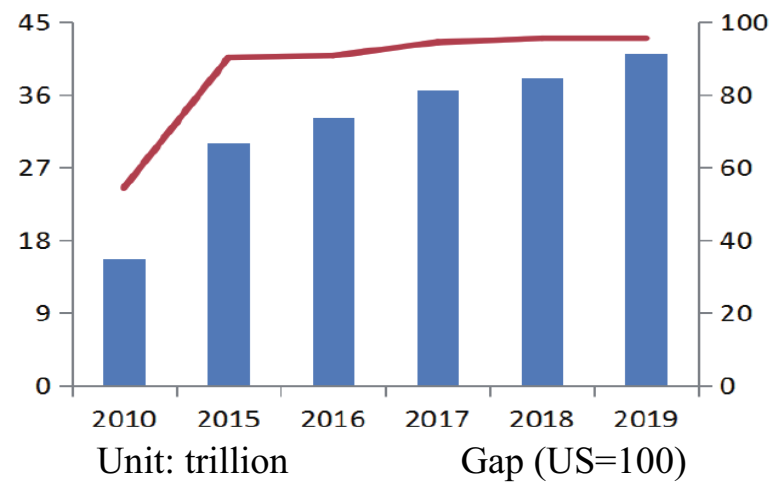

The total retail sales of social consumer goods The gap with the U.S.

Figure 2. The gap between the growth of my country's total retail sales of consumer goods and the United States

\subsection{Persist in accelerating circulation and improve overall resource allocation efficiency}

Speed up the construction of a strong transportation country and improve the transportation infrastructure. Although China's high-speed rail has the largest mileage in the world at present, due to its large area and complicated terrain, there are still many places with relatively backward traffic conditions, people have difficulty traveling, and the transportation of commodities, especially agricultural products, is difficult. It is necessary to accelerate the construction of transportation infrastructure in the central and western regions, and promote the integration of the central and western regions into the national economic development cycle. Reduce logistics costs and promote commodity circulation. It is necessary to further reduce oil and gas prices, lower highway toll rates, lower railway and air freight charges, standardize maritime port charges, promote the construction of logistics infrastructure networks, reduce the cost of logistics, human flow, and capital flow, and speed up the process of commodity circulation.

\subsection{Persist in the distribution of labor subjects, and improve the distribution system of narrowing the gap and sharing the wealth ${ }^{[6]}$}

Adhere to the distribution of labor entities, improve the distribution system of narrowing the gap and sharing the wealth, control the growth rate of the wealth of the rich, raise the level of middle and low income, and improve the ability to protect people's livelihood. Improve the social security system, enhance the security capacity of informal employment groups, further improve the education, housing, and medical systems, improve the level of people's livelihood security, further improve employment, improve employment skills, and ensure a stable source of income for low- and middle-income earners . Build a more just and reasonable international order and improve the international wealth distribution system. China must actively participate in and lead the reform of the global governance system, adhere to mutual benefit and win-win results, and establish a more just and reasonable international wealth distribution system in accordance with the principle of equality and mutual benefit.

\subsection{Adhere to the principle of self-reliance and openness, and promote the fair development of economic globalization ${ }^{[7]}$}

Adhere to the principle of self-reliance, leading and openness, and promote the development of economic globalization. First, promote higher-level, deeper, and stronger opening to the outside world. Although there is a phenomenon of anti-globalization, it cannot stop the trend of globalization, and a country cannot stop the process of globalization. It is necessary to promote the establishment of a higher level and deeper level of opening to the outside world, using free trade zones, new areas, and free trade ports as starting points to promote trade facilitation, investment liberalization, financial internationalization, management modernization, regulatory legalization, and globalization Develop in depth. Second, promote the international cycle. China needs to play a more active role in global economic governance. Make full use of the United Nations, the World Bank, and the International Monetary Fund to unite with developing countries to build a more just and reasonable international order. It is necessary to reduce the trade surplus and promote the balance of international payments. It is necessary to increase international imports to better satisfy people's lives. It is necessary to promote Chinese enterprises to go global and make better use of foreign markets and foreign resources. Promote fairer and fairer international trade, break international trade barriers, promote the healthy development of the world market, and smooth the international cycle. Third, promote the mutual promotion of domestic and international dual cycles. Promote the construction of the "Belt and Road", make better use of both domestic and international markets and resources, develop the spirit of self-reliance, independence, selfreliance, and self-reliance, and correctly handle the relationship between self-reliance and opening up. With the healthy development of the domestic cycle and the smooth development of the international cycle, a new 
development pattern can be formed in which the two promote each other and develop sound development, and promote the construction of human destiny in the cooperative game and great struggle against unilateralism and hegemonism.

\section{Conclusion}

In summary, starting from the unblocked doublecirculation blocking point, the implementation strategy to promote the new development pattern is studied. It has important practical significance for activating and digging into the domestic market space and coping with the complex and complex globalization impact.

\section{References}

1. Xi Jinping.(2020) Several Major Issues in the National Medium and Long-term Economic and Social Development Strategy.Seeking Truth, No. 21, 2020, page 5

2. Xu Xianchun.(2021) Analysis of China's Economic Situation in 2020 and Prospects for 2021. Economic Trends, 2021, (01):34-35

3. Xu Xianchun.(2021) Analysis of China's Economic Situation in 2020 and Prospects for 2021. Economic Trends, 2021, (01):34-35

4. Xi Jinping.(2020) Speech at the Entrepreneur Forum.In Chinese People's Publishing House, Beijing. page 10.

5. Karl Marx.(2012) Selected Works of Marx and Engels (Volume 2). In Chinese People's Publishing House, Beijing ,pages 689- 699.

6. Cheng Enfu.(2021) Political Economics Analysis of the New Development Pattern of "Double Cycles". Quest,page41-42

7. Cheng Enfu.(2021) Political Economics Analysis of the New Development Pattern of "Double Cycles". Quest,page42-43 